\title{
ÁREAS PÚBLICAS OCIOSAS: DIRETRIZES PROJETUAIS PARA IMPLANTAÇÃO DE HABITAÇÃO SOCIAL E EQUIPAMENTOS URBANOS
}

\author{
Valquíria Pereira Bastos ${ }^{1}$, Mayara Pissuti Albano² \\ Universidade do Oeste Paulista - UNOESTE, Faculdade de Engenharias e Arquitetura e Urbanismo, \\ Presidente Prudente, SP. E-mail: ma.albano@unoeste.br
}

\section{RESUMO}

O acelerado processo de urbanização brasileira trouxe consequências para a questão habitacional no país, desencadeando um processo de exclusão sócio espacial; para minimizar as baixas condições de urbanidade, foram criadas as áreas públicas, que hoje encontram-se com ocupações irregulares, descaso e falta de manutenção adequada em algumas cidades, principalmente em bairros de baixa renda. Nesse sentido, esse artigo busca contribuir com análises sobre a produção da habitação social e a ratificação da implantação de áreas públicas através da contextualização histórica dos temas, bem como apresentar diretrizes projetuais para a implantação de conjunto habitacional aliado à áreas públicas. A metodologia usada baseia-se em levantamentos bibliográficos, documentais e pesquisas de campo.

Palavras chave: Habitação Social, Áreas Públicas, Equipamentos Urbanos, Diretrizes projetuais, Presidente Prudente - SP.

\section{IDLE PUBLIC AREAS: PROJECTIVE GUIDELINES FOR IMPLEMENTATION OF PUBLIC HOUSING AND URBAN EQUIPAMENTS}

\begin{abstract}
The accelerated Brazilian urbanization process has brought consequences for the housing problem in the country, triggering a socio-spatial exclusion process; to minimize casualties conditions of urbanity, the public areas were created, which today are filled with irregular occupations, neglect and lack of proper maintenance in some cities, especially in low-income neighborhoods. In this sense, this article seeks to contribute to the analysis of production of public housing and the ratification of the implementation of public areas through the historical context of the themes, as well as presenting projective guidelines for the public housing project implementation with the public areas. The methodology is based on bibliographic and documentary surveys. Keywords: Social Housing, Public Areas, Urban Equipment, Project Guidelines, Presidente Prudente - SP.
\end{abstract}




\section{INTRODUÇÃO}

O Brasil vivenciou um grande crescimento no setor econômico no último século, implicando diretamente no desenvolvimento urbano das cidades e, consequentemente, influenciando no problema habitacional do país (AKAISHI, 2013). A expansão das cidades sem planejamento adequado, aliado a concentrações de trabalhadores e população menos privilegiadas ocasionaram esse acumulo de problemas, incluindo a segregação social e a crise urbana (BONDUKI, 2004).

Mesmo com os vários investimentos públicos e privados no setor habitacional, as cidades brasileiras ainda contam com condições baixas de urbanidade (AKAISHI, 2013) e, como uma forma de minimizar essa situação, foram instituídos instrumentos normativos para a organização de novas áreas urbanas, possibilitando a criação de normas em relação às áreas públicas. Entretanto, muitas dessas áreas possuem desvios de finalidade, onde acabam sendo ocupadas irregularmente ou se entregam ao descaso do poder público local (DE SOUZA; FRANCISCO, 2013).

Nesse contexto, este trabalho tem como objetivo apresentar diretrizes projetuais para a implantação de projeto de habitação social aliado à equipamentos urbanos de lazer e institucionais, unindo as áreas públicas ao projeto de habitação, possibilitando a criação de um complexo multifuncional com espaços públicos e unidades residenciais com qualidade.

O presente trabalho foi desenvolvido a partir de pesquisas bibliográficas, onde os dados encontrados foram discutidos de maneira crítica-reflexiva, identificando a área de conhecimento e realizando pesquisas sobre o objeto de estudo. Foi realizada também a pesquisa documental, a partir do Inquérito Civil - IC № MP : 14.0720.0000322/2.011-1, que registra as áreas livres urbanas em Presidente Prudente, e de tal forma, pôde-se se levantar a área escolhida como objeto de estudo. Num terceiro momento, a pesquisa de campo foi realizada para levantar os fatos a partir da observação do local de implantação, com fotografias, medições e anotações sobre a referida área. Dessa forma, foram analisados os dados encontrados para a obtenção de melhores resultados do trabalho agora apresentado.

\section{O ESPAÇO URBANO, ÁREAS PÚBLICAS E O ACESSO À MORADIA}

Ao longo da história da colonização do Brasil, o território foi se organizando de maneira distinta e esparsa, recentemente, em meados do século $X X$, o processo de urbanização se tornou intenso. Houve um aumento considerável da população urbana e, a partir desse momento o grande crescimento urbano dá início ao processo de exclusão social, quando as cidades começaram a ganhar novas proporções e iniciou-se o problema da habitação (MARICATO, 2008).

Nas primeiras décadas do século XX, a moradia de aluguel era uma das principais formas para a solução da questão da habitação, porém em 1942 o governo interferiu nesse mercado, e através da política instituída difundiu-se o pensamento de que a casa própria representava o progresso material, pensamento que predomina a maioria da população ainda hoje (BONDUKI, 2004). Diminuir a atratividade do setor imobiliário impulsionou o acesso à formas alternativas de moradia, visto que a população começou a ocupar a periferia em locais sem nenhum tipo de infraestrutura ou saneamento, com a criação das favelas e loteamentos irregulares, pois, essa era a única forma de conseguir a casa própria. Desde então, o trinômio loteamento popular/casa própria/autoconstrução se tornou uma das formas predominantes de assentamento residencial da classe trabalhadora (MAUTNER, 2010). O resultado dessas ações trouxe como consequência, o aumento da malha urbana e da segregação sócio espacial.

Dessa forma, aliado a expansão territorial desenfreada, as periferias segregadas incorporaram a precariedade urbanística, mobilidade restrita, ausência de regulação social, ambiental e de atividades culturais, de modo que as condições socioeconômicas da população de baixa renda não tenha possibilidade de melhorias (MARICATO, 2008). Nesse contexto, foram necessárias diversas propostas normativas visando a intervenção no processo de urbanização e na 
qualidade de vida das cidades, limitando e ordenando seu crescimento (DE SOUZA; FRANCISCO, 2013), uma delas a lei que regulamentava as áreas públicas nos novos loteamentos.

Nesse contexto, é criada a Lei 6.766, em dezembro de 1979, atualizada em 1999 por meio da Lei Federal no 9.785, que dispõe sobre o Parcelamento do Solo Urbano no Registro Imobiliário. A lei tem como objetivo reverter o panorama das cidades brasileiras estabelecendo normas para áreas ambientalmente frágeis, faixas não edificáveis, áreas de uso público e vias públicas referentes à loteamentos e desmembramentos (DE SOUZA; FRANCISCO, 2013).

Surge então o conceito de áreas livres públicas na cidade, impondo aos novos loteamentos a existências de áreas destinadas a implantação de equipamento urbano e comunitário, bem como a espaços livres de uso público, que consistem em equipamentos públicos de educação, cultura, saúde, lazer e similares (BRASIL, 1979, art. 4ㅇ).

De acordo com a Lei do Parcelamento do Solo Urbano, no Registro Imobiliário, os espaços livres de uso comum e áreas institucionais não poderão ter sua destinação alterada pelo loteador (BRASIL, 1979, art. 17ㅇ). Entretanto, em muitos casos, quando não acontece a devida implantação dos equipamentos propostos no projeto do loteamento, as áreas podem sofrer ocupações irregulares. Com o déficit de moradias, as pessoas recorrem à posse dessas áreas vagas, muitas vezes sem qualquer segurança ou salubridade (BARREIROS; ABIKO, 1998).

A inexistência do equipamento urbano ou área de lazer e a presença de ocupações ilegais são ignoradas pelo Estado, principalmente, se localizadas na periferia. Dessa forma, muitas áreas destinadas à comunidade são fragmentadas de acordo com o desenho urbano, possibilitando um maior número de lotes, e consequentemente, do lucro sobre o terreno urbano, descaracterizando a função social da terra (LIMA; AMORIM, 2006).

A carência de moradias ainda constitui um grave problema para os governos federal, estaduais e municipais; em 2013 o déficit para residências que deveriam ser construídas correspondem a 5,846 milhões de domicílios (FUNDAÇÃO JOÃO PINHEIRO, 2015). Nesse contexto, com a dificuldade de acesso à terra urbana e à habitação por meio legal, a população acaba ocupando áreas públicas ou particulares abandonadas, áreas de proteção ambiental, encostas ou embaixo de pontes e viadutos. Essa realidade, apesar de maior nas metrópoles brasileiras, acontece também em cidades médias, pois é uma das únicas formas que a população de mais baixa renda tem encontrado em relação à falta de opção de moradia (LORENZETTI, 2001).

\section{PRESIDENTE PRUDENTE - SP, ÁREAS PÚBLICAS E HABITAÇÃO SOCIAL: LOCAL ESCOLHIDO}

Presidente Prudente é uma cidade média do interior do estado de São Paulo e, atualmente, tem mais de duzentos mil habitantes (IBGE, 2010) e a questão da habitação social ainda não tem recebido a devida atenção por parte da Prefeitura, legislação e planejamento (HONDA, 2011). A área de estudo escolhida se localiza na região sudeste da cidade, com uma expansão desacelerada, declive acentuado e voltado para a população de baixo poder aquisitivo.

O terreno foi escolhido por ser um dos vazios urbanos dentro da malha consolidada na região sudeste da referida cidade (Figura 1), com infraestrutura adequada para a população. Dessa forma, elimina-se o espaço residual naquela região e reestrutura-o para uma nova forma de ocupação, aliando a habitação para pessoas de baixa renda e áreas públicas voltadas à população, tanto institucionais quanto de lazer.

No Brasil, foi a partir dos conceitos da arquitetura moderna que surgiram as primeiras mudanças tipológicas nos projetos habitacionais, aliando as células de habitação com equipamentos sociais e comunitários. Dessa forma, modificou-se a relação entre público e privado, unindo a Arquitetura e Urbanismo através da relação entre moradia, equipamentos coletivos e a cidade (BONDUKI, 2004). 
Segundo Honda (2011), não há loteamos novos na região desde 2000, completando mais de 15 anos desde a última ocupação, já que os outros investimentos no setor habitacional se consolidaram em áreas opostas a estudada.
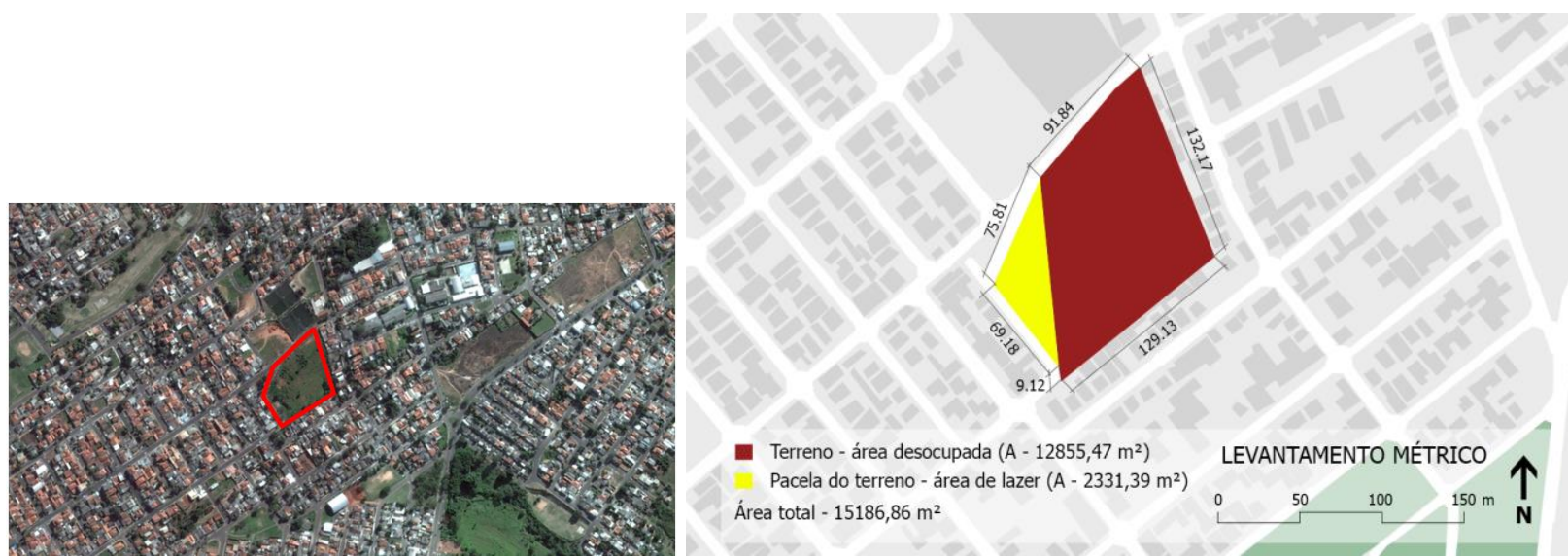

Figura 01. Área de estudo

Fonte: Google Earth (2016) / Prefeitura de Presidente Prudente (2015), modificado por Bastos (2016)

Apesar de não estar loteada, a área já recebeu ocupações irregulares, como pode ser observado na Figura 2. Nota-se a construção provisória com uso de materiais precários, confirmando que as parcelas mais pobres da população ainda tem dificuldade ao acesso legal à terra, e que essa exclusão tem grande impacto na produção do espaço urbano.

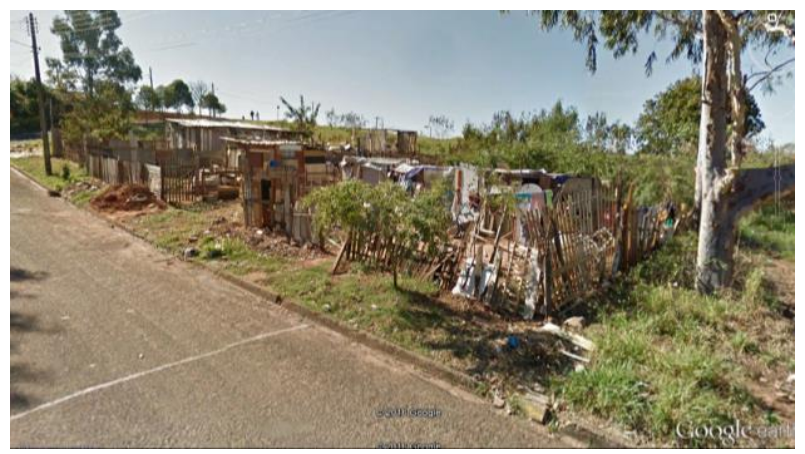

Figura 02. Ocupações no terreno em 2011

Fonte: Google Earth (2016)

O desnível presente no terreno poderá proporcionar novas soluções para o projeto do Conjunto Habitacional e Complexo Multifuncional, além de viabilizar o uso do declive para criar pavimentos diferenciados, como pode ser visto no corte da Figura 3. Através da skyline, também é possível compreender a relação do entorno com o terreno, onde nota-se o baixo gabarito de altura e o grande vazio que se encontra em grande parte na face principal do terreno (Vista 1). Quanto as outras faces do terreno, a Vista 2 está voltada para residências e as Vistas 3 e 4 fazem fundo para outras moradias. 


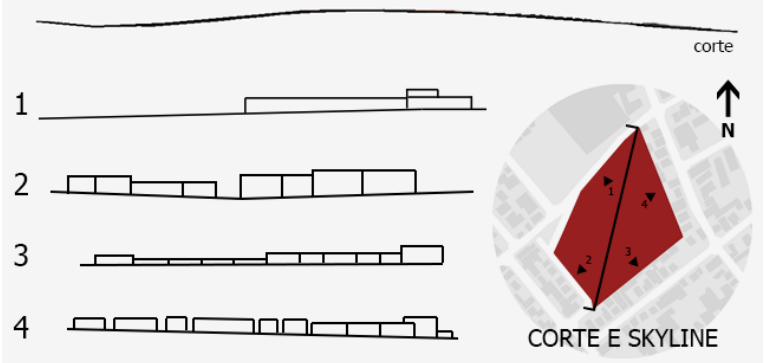

Figura 03. Corte e Skyline

Fonte: Google Earth (2016), modificado por Bastos (2016)

O terreno escolhido para a intervenção possui um entorno basicamente residencial, com alguns comércios de bairro, instituições religiosas e alguns terrenos ainda não ocupados. Quanto as áreas públicas, encontra-se a área de lazer em bairros vizinhos apenas. Há um Posto de Saúde da Família e duas escolas que atendem a região. A maioria das edificações do entorno possuem apenas um pavimento; a região ainda apresenta muitas áreas vazias de grandes dimensões, influenciando a paisagem.

O terreno de intervenção possui uma barreira visual, pois dele é possível visualizar o Depósito de Lixos de Presidente Prudente. Apesar de estar localizado no Distrito Industrial, os bairros da região leste, em sua maioria, possui visão para o local, também conhecido como "Lixão" (Figura 4). Fato que influenciará nas diretrizes projetuais e escolha dos equipamentos públicos que irão compor o projeto arquitetônico.
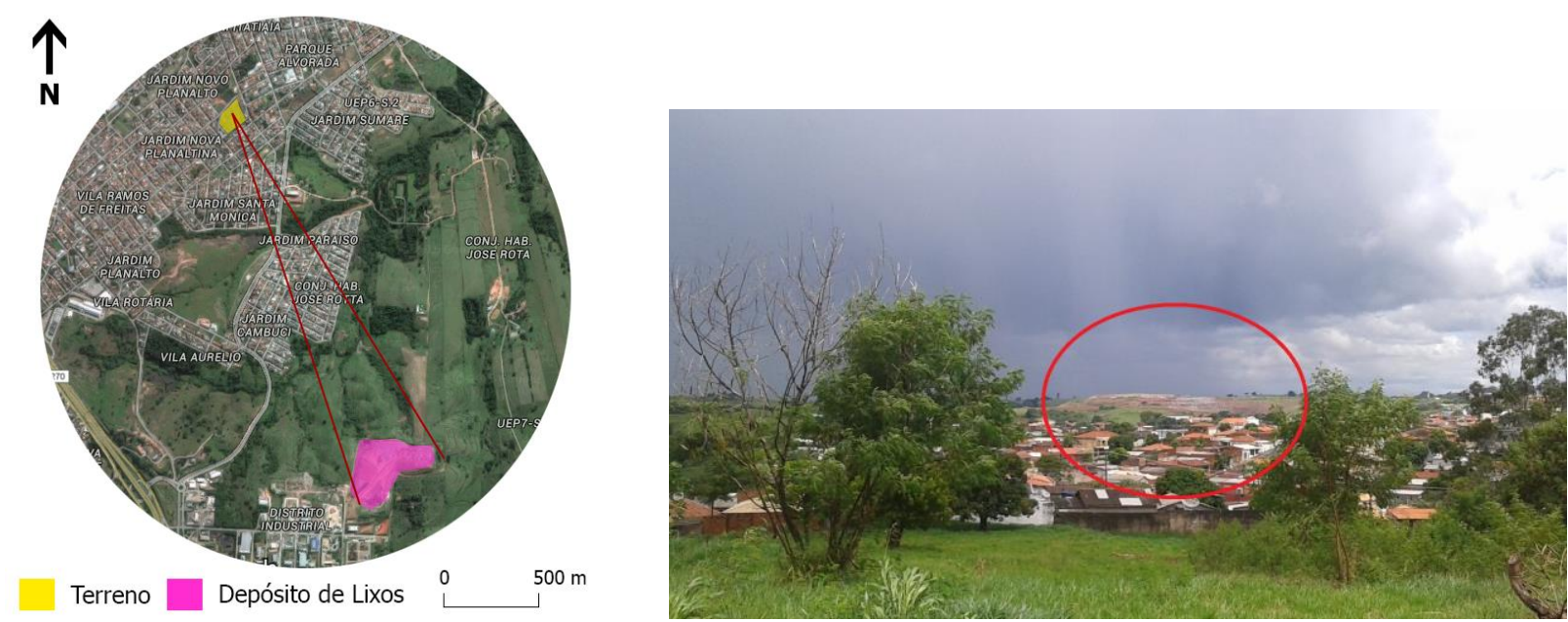

Figura 04. O terreno e o Depósito de Lixo

Fonte: Google Maps (2016), modificado pela autora (2016) / Bastos (2016)

Através das análises realizadas neste capítulo, é possível compreender melhor o terreno escolhido para a intervenção, viabilizando atitudes de projeto que respeitem as características do entorno, meio ambiente e a residentes do local. Dessa forma, através de um conjunto habitacional aliado à um complexo multifuncional, ameniza-se os desvios de finalidade das áreas públicas e as consequências causadas pela proximidade com um depósito de lixos, de tal modo que se crie um ambiente de melhor qualidade para a população de baixa renda dos bairros próximos.

\section{DIRETRIZES PROJETUAIS}

As diretrizes projetuais foram definidas a partir das análises realizadas do local de intervenção e das referências escolhidas, além de seguir os preceitos habitacionais da CDHU. 
Contatou-se a partir de análises do terreno que seu entorno é formado em sua maioria por residências; dessa forma, o projeto mantém a ocupação do bairro, através do conjunto habitacional. De acordo com o zoneamento local (ZR2), o gabarito de altura das construções devem ser de até dois pavimentos; entretanto, caso o primeiro pavimento seja composto totalmente por garagem, admite-se três pavimentos; por conseguinte, o conjunto será implantado em blocos de dois e três pavimentos, seguindo a legislação.

O projeto tem como objetivo a devolução das áreas públicas que tiveram suas finalidades alteradas na microrregião onde se encontra; entretanto, sabe-se que próximos ao local existem instituições voltados à saúde e educação; nesse sentido, os equipamentos implantados no complexo multifuncional serão voltados ao lazer, além de espaços para a realização de cursos e oficinas direcionados à população.

Além disso, busca-se a integração entre os espaços públicos e o conjunto habitacional; para que isso aconteça, elimina-se a delimitação das áreas públicas e privadas por muros e grades. Também serão implantadas passarelas de acesso entre os edifícios, criando circulações para os moradores entre os prédios residenciais.

Para minimizar o impacto ambiental do conjunto e complexo, usa-se a ventilação cruzada, a integração com o meio ambiente, materiais reciclados e que não causem impacto na natureza, além da implantação da coleta de lixo subterrânea, já usada na cidade de Presidente Prudente em alguns locais.

Quanto às diretrizes da CDHU, usa-se a metragem quadrada indicada e o programa de necessidades para as unidades residenciais, compostas por: sala, cozinha, lavanderia, banheiro e dois dormitórios. Em função do conceito e partido arquitetônico, não serão seguidas as técnicas construtivas indicadas.

\section{CONCLUSÃO}

Através de uma revisão da produção habitacional no Brasil é possível compreender a quantidade insuficiente do número de moradias nos dias atuais e a relevância desse estudo para o país. Reflete-se também a ratificação da lei perante as áreas públicas e sua importância para a qualidade de vida da população urbana das regiões periféricas. Nesse contexto, os novos conjuntos habitacionais devem ser projetados a partir da observação de erros e acertos do passado, aliado às novas políticas urbanas para que ocorra a diminuição da segregação sócio espacial e da especulação imobiliária e o consequente aumento da qualidade de vida e na infraestrutura desses loteamentos. Isso é possível através da integração dos equipamentos urbanos aos conjuntos habitacionais, aliando o espaço público e o privado.

\section{REFERÊNCIAS}

AKAISHI, A. G. Desafios do planejamento urbano-habitacional em pequenos municípios brasileiros à luz da nova política nacional de habitação. In: Encontros Nacionais da ANPUR, 15., 2013, Recife. Anais eletrônicos... Recife, 2013. Disponível em: <http://unuhospedagem. com.br > Acesso em: 18 nov. 2015

ALBANO, M.P. A importância do Planejamento urbano ambiental: a habitação social e a expansão urbana em Presidente Prudente - SP. 2013. 165 f. Dissertação (Mestrado em Desenvolvimento Regional) - Universidade do Oeste Paulista, Presidente Prudente - SP. Disponível em: <http://apeclx.unoeste.br>. Acesso em: 14 set. 2015

BARREIROS, M. A. F.; ABIKO, A. K. Reflexões sobre o Parcelamento do Solo Urbano. Boletim Técnico da Escola Politécnica da USP. 1998. Disponível em: <http://allquimica.locaweb. com.br > Acesso em: 18 mar. 2016 
BENINI, S. M; MARTIN, E. S. Decifrando as áreas verdes públicas. In: Revista Formação, Brasil, 2010, 17, v. 2, p. 63-80. Disponível em: < http://revista.fct.unesp.br> Acesso em: 02 mar. 2016

BRASIL. Lei n.6.766, de 19 de dezembro de 1979. Dispõe sobre o parcelamento do solo urbano e dá outras providências. Disponível em: <https://www.planalto.gov.br > Acesso em 8 mar. 2016

BONDUKI, N. G. Origens da habitação social no Brasil: arquitetura moderna, lei do inquilinato e difusão da casa própria. 4ạ Ed. São Paulo: Estação Liberdade, 2004.

DE SOUZA, M. B. S. D; FRANCISCO, J. O parcelamento do solo urbano e a desconstrução espacial. In: Encontros Nacionais da ANPUR, 15., 2013, Recife. Anais eletrônicos... Recife, 2013. Disponível em: <http://unuhospedagem.com.br> Acesso em: 17 mar. 2016

FUNDAÇÃO JOÃO PINHEIRO. Centro de Estatística e Informações. Déficit Habitacional no Brasil 2013: resultados preliminares. Nota Técnica. Belo Horizonte, 2015. Disponível em: <http://www.fjp.mg.gov.br> Acesso em: 03 mar. 2016

HONDA, S. Habitação de baixa renda como produto do capital: o Programa de Arrendamento Residencial (PAR) em Presidente Prudente - SP. 2011

LIMA, V.; AMORIM, M. A importância das áreas verdes para a qualidade ambiental das cidades. In: Revista Formação, Brasil, 2006, 13, v. 1, p. 69-82. Disponível em: <http://revista.fct.unesp.br> Acesso em: 24 jun. 2014.

LORENZETTI, M. S. B. A questão habitacional no Brasil. Brasília: Consultoria Legislativa da Câmara dos Deputados, junho/2001 (Relatório). Disponível em: <http://bd.camara.leg.br> Acesso em: 22 fev. 2016

MARICATO, E. Brasil, cidades: alternativas para a crise urbana. 3a Ed. Petrópolis, RJ: Vozes, 2008. 